\title{
Does co-payment for inhaler devices affect therapy adherence and disease outcomes? A historical, matched cohort study
}

This article was published in the following Dove Press journal:

Pragmatic and Observational Research

I8 April 2017

Number of times this article has been viewed

\author{
Jaco Voorham' \\ Bernard Vrijens ${ }^{2}$ \\ Job FM van Boven ${ }^{3,4}$ \\ Dermot Ryan ${ }^{5}$ \\ Marc Miravitlles ${ }^{6}$ \\ Lisa M Law' \\ David B Price ${ }^{1,7}$
}

'Observational \& Pragmatic Research Institute Pte Ltd, Singapore,

Singapore; ${ }^{2}$ Department of Public Health Sciences, Faculty of Medicine, University of Liège, Liège, Belgium; ${ }^{3}$ Unit of PharmacoEpidemiology and PharmacoEconomics, Department of Pharmacy, ${ }^{4}$ Department of General Practice, Groningen Research Institute for Asthma and COPD, University Medical Center Groningen, University of Groningen, Groningen, The Netherlands; ${ }^{5}$ Allergy and Respiratory Research Group, University of Edinburgh, Edinburgh, UK, ' Department of Pulmonology, Hospital Universitari Vall d'Hebron, Barcelona, Catalonia, Spain; ${ }^{7}$ Academic Primary Care, The Institute of Applied Health Sciences, University of Aberdeen, Aberdeen, UK

Correspondence: David B Price Academic Primary Care, The Institute of Applied Health Sciences, University of Aberdeen, Polwarth Building, Foresterhill, Aberdeen AB25 2ZD, UK

Tel +44 I223967855

Fax +44 I224550683

Email dprice@opri.sg
Background: Adherence to asthma and chronic obstructive pulmonary disease (COPD) treatment has been shown to depend on patient-level factors, such as disease severity, and medicationlevel factors, such as complexity. However, little is known about the impact of prescription charges $-\mathrm{a}$ factor at the health care system level. This study used real-life data to investigate whether co-payment affects adherence (implementation and persistence) and disease outcomes in patients with asthma or COPD.

Methods: A matched, historical cohort study was carried out using two UK primary care databases. The exposure was co-payment for prescriptions, which is required for most patients in England but not in Scotland. Two comparison cohorts were formed: one comprising patients registered at general practices in England and the other comprising patients registered in Scotland. Patients aged 20-59 years with asthma, or 40-59 years with COPD, who were initiated on fluticasone propionate/salmeterol xinafoate, were included, matched to patients in the opposite cohort, and followed up for 1 year following fluticasone propionate/salmeterol xinafoate initiation. The primary outcome was good adherence, defined as medication possession ratio $\geq 80 \%$, and was analyzed using conditional logistic regression. Secondary outcomes included exacerbation rate. Results: There were 1,640 patients in the payment cohort, ie, England (1,378 patients with asthma and 262 patients with COPD) and 619 patients in the no-payment cohort, ie, Scotland (512 patients with asthma and 107 patients with COPD). The proportion of patients with good adherence was $34.3 \%$ and $34.9 \%$ in the payment and no-payment cohorts, respectively, across both disease groups. In a multivariable model, no difference in odds of good adherence was found between the cohorts (odds ratio, 1.04; 95\% confidence interval, 0.85-1.27). There was also no difference in exacerbation rate.

Conclusion: There was no difference in adherence between matched patients registered in England and Scotland, suggesting that prescription charges do not have an impact on adherence to treatment.

Keywords: implementation, adherence, asthma, chronic obstructive pulmonary disease, prescriptions, co-payment

\section{Background}

Asthma and chronic obstructive pulmonary disease (COPD) are two leading causes of morbidity and economic burden worldwide, with 300 and 210 million people affected, respectively. ${ }^{1}$ Both these diseases are chronic obstructive lung conditions principally managed with inhaled therapies, such as inhaled corticosteroids (ICS). Effectiveness of therapy, however, can be adversely affected by poor adherence. ${ }^{2}$ Adherence is defined as the process by which patients take their medications as prescribed, comprising 
1) initiation of treatment, 2) implementation of the dosing regimen, and 3) persistence with treatment. ${ }^{3}$ Previous literature has demonstrated that poor adherence can exist among patients with asthma or $\mathrm{COPD}^{4-6}$ and has an impact on disease outcomes. ${ }^{7-9}$ Contributing factors to poor adherence at the patient level include perceived need of treatment, ${ }^{10}$ fear of side effects, ${ }^{11}$ and ability to use inhaler devices correctly. ${ }^{12,13}$ Less research has been done into contributing factors at the health care system level.

One potential factor is co-payment for prescriptions. In an attempt to scale back on pharmaceutical spending, many countries have introduced co-payment policies to offset growing drug bills. ${ }^{14-16} \mathrm{~A}$ co-payment is a fixed fee for a prescription, which is intended to reduce drug expenditure and the collection of medications that have no role in improving health. ${ }^{17}$ However, co-payments may be disadvantageous if they result in a decrease in the use of beneficial medication. A study in Australia found that a $24 \%$ increase in patient co-payment for medications had significant effects on the dispensing of some essential drugs, including decreased volumes of dispensed asthma medications. ${ }^{18}$ The more vulnerable patient populations are those that have an increased sensitivity to adverse health outcomes, such as the elderly and those with low socioeconomic status. ${ }^{19} \mathrm{~A}$ review of 22 studies in the USA between 1990 and 2003 found that copayments were associated with a decrease in the health status of older patient groups. ${ }^{20}$

Currently, in England, for residents nonexempt from paying for prescriptions, there is a flat rate patient contribution of $£ 8.40$ per prescription. ${ }^{21} \mathrm{~A}$ resident of England can cap the prescription cost by purchasing a monthly (£29) or annual (£104) prescription prepayment certificate (PPC). In contrast, Scotland canceled co-payments on prescriptions in 2011. ${ }^{22}$ This difference in prescription payments in England and Scotland, and the availability of real-life primary care data over time, allows an opportunity to examine the effects of prescription co-payment.

The aim of this study was to use real-life data to examine the impact of co-payment on maintenance therapy implementation and persistence and disease outcomes in patients with asthma or COPD, accounting for differences between the populations.

\section{Methods}

\section{Data source and permissions}

This study used data from the Optimum Patient Care Research Database (OPCRD $)^{23}$ and the Clinical Practice Research Datalink (CPRD) ${ }^{24}$ Both are primary care databases with routinely recorded clinical data from general practices in the UK. The OPCRD has anonymized data from $>3$ million patients in $>570$ UK practices, and the CPRD has anonymized data from $>5$ million patients in $>600$ UK practices. The databases contain a range of information, including prescribing activity and diagnoses of disease, identifiable by Read codes recorded by clinicians. The CPRD (formerly GPRD) is well validated and used frequently for medical and health research. ${ }^{24,25}$ The OPCRD has been used in numerous studies of real-life effectiveness in respiratory diseases: ${ }^{26-29}$ the validity of the real-life endpoints commonly identified in the OPCRD (such as risk-domain asthma control) has been supported previously in a study showing the predictive value of real-life endpoints for future patient outcomes. ${ }^{30}$

The OPCRD has ethical approval from the National Health Service (NHS) Research Authority to hold and process anonymized research data (Research Ethics Committee reference: 15/EM/0150). This study was approved by the Anonymised Data Ethics Protocols and Transparency (ADEPT) committee - the independent scientific advisory committee for the OPCRD, commissioned by the Respiratory Effectiveness Group. ${ }^{31}$ Informed consent was not required from the participants, as this was a retrospective study, and all data was anonymized. The study is registered with the European Network of Centres for Pharmacoepidemiology and Pharmacovigilance (ENCEPP/SDPP/13586). ${ }^{32}$

\section{Study design}

A historical, matched cohort study design was used to compare patients with asthma or COPD with likely co-payment with patients with asthma or COPD with no co-payment for prescriptions, in terms of their adherence to fluticasone propionate/salmeterol xinafoate (FP/SAL) therapy. We chose $\mathrm{FP} / \mathrm{SAL}$ as we aimed to examine adherence to maintenance therapy only and so did not select medications that are used as both maintenance and reliever therapy. The cohorts will be referred to as the payment cohort (patients from general practices in England) and the no-payment cohort (patients from general practices in Scotland). The study period consisted of 2 years - a baseline year for patient characterization and identification of suitable matching variables and an outcome year for observing the outcomes of interest. The baseline and outcome years were separated by an index date, which was the date of first prescription of FP/SAL.

\section{Inclusion and exclusion criteria}

Patients were selected based on the following inclusion criteria: diagnosis for asthma and/or COPD; received prescription for FP/SAL, with no prescription in the preceding year; aged $\geq 40$ and $<60$ years at the index date (date of initial 
prescription of $\mathrm{FP} / \mathrm{SAL}$ ) for patients with $\mathrm{COPD}$, and aged $\geq 20$ and $<60$ years at the index date for patients with asthma; at least 2 years of valid, continuous data (at least 1 year before and at least 1 year after the index date); and at least one further prescription for FP/SAL during the outcome period. The upper age boundary of 60 years was used because patients aged $\geq 60$ years are exempt for co-payment in England.

Patients were excluded if they had any chronic respiratory disease other than asthma or COPD, at any time, or they met other conditions for co-payment exemption, which included being pregnant during or in the 12 months prior to the study period, record of "prescription exemption status" before or during the study period, and hospitalization during the study period.

Patients with only an asthma diagnosis were considered the "asthma group", and patients with a COPD diagnosis, who may or may not have had an asthma diagnosis in addition, were considered the "COPD group". Thus, there was no overlap between the two groups.

\section{Outcome measures}

The primary outcome was adherence to FP/SAL therapy over the 1-year outcome period. This was evaluated in terms of the percentage of prescription refill rate, with good adherence being defined as a medication possession ratio (MPR) $)^{33}$ of $\geq 80 \%$. The normal duration of a prescription in the UK is 30 days. Since the MPR was assessed in a fixed 1-year period, this adherence measure incorporates both implementation and persistence. Details of the calculations used to compute MPR can be found in the Supplementary materials.

Secondary outcome measures included number of severe exacerbations (or moderate/severe exacerbations for patients in the COPD group), risk-domain control, average daily dose of short-acting beta ${ }_{2}$ agonist (SABA), and number of acute respiratory events (patients in asthma group).

The definition of severe asthma exacerbations was the sensitive definition based on the American Thoracic Society/ European Respiratory Society (ATS/ERS) guidelines. ${ }^{34}$ A severe exacerbation included one or more occurrences of any of the following: asthma-related hospital admission or accident and emergency (A\&E) attendance and an acute course of oral corticosteroids (OCS) with lower respiratory consultation.

For patients in the COPD group, a moderate or severe exacerbation included one or more occurrences of any of the following: COPD-related, unscheduled hospital admission or A\&E attendance; an acute course of OCS with lower respiratory consultation; and antibiotics prescribed with lower respiratory consultation. The risk-domain control of COPD was defined as the absence of any moderate/severe exacerbations.

For patients in the asthma group, an acute respiratory event was defined as one or more occurrences of any of the following: asthma-related hospital admission or A\&E attendance; an acute course of OCS; and antibiotics prescribed with lower respiratory consultation. The risk-domain control of asthma was defined as the absence of any acute respiratory events.

Finally, the average daily dose of SABA during the outcome year was calculated as the average number of puffs per day over the year multiplied by the strength of dose (in $\mu \mathrm{g}$ of salbutamol equivalents).

More detailed definitions of the above outcomes can be found in the Supplementary materials.

\section{Statistical analysis}

\section{Baseline characterization}

Baseline variables were summarized and compared between cohorts. This was done separately in the asthma and COPD groups to identify potential matching variables, ie, those that differed between cohorts. Binary and categorical variables were summarized using counts and percentages by category. Continuous variables were summarized using mean and standard deviation or median and interquartile range. Variables were compared between cohorts to assess imbalance and bias potential. Imbalance was measured using the standardized mean difference (SDD) ${ }^{35}$ between cohorts, while bias potential was measured using the relative change in coefficient (RCC). ${ }^{36}$

\section{Matching}

The baseline variables with high bias potential $(>2 \%)$ and high level of imbalance (SDD $>10 \%)^{37}$ were considered for matching. This was done separately within the asthma group and the COPD group, ie, patients with asthma only were matched with patients with asthma only (which formed the matched asthma group) and patients with COPD were matched with patients with COPD (which formed the matched COPD group), regardless of coexisting asthma diagnosis. Exact matching combined with a propensity score was carried out with a mixture of ratios of patients in the nopayment cohort to patients in the payment cohort $(1: 1,1: 2$, and 1:3). After matching, bias potential was again assessed to identify areas where residual confounding was present for the different outcomes. More details on matching methods can be found in the Supplementary materials. 


\section{Outcome analysis}

Conditional logistic regression was used to compare the odds of good adherence of patients in the payment cohort with that of the matched patients in the no-payment cohort. This was carried out in the asthma and COPD groups combined.

Conditional logistic regression was used to estimate odds ratios (ORs) for risk-domain control, comparing the payment cohort with the no-payment cohort. Conditional Poisson regression was used to estimate rate ratios (RRs), for the number of severe exacerbations (or moderate/severe in the COPD group) and the number of acute respiratory events (in the asthma group only). Finally, ordinal logistic regression was used to estimate the proportional odds of being in a higher category of SABA dose. For this analysis, the average daily dose of SABA was categorized as $0,>0-200,>200-400$, $>400-600$, and $>600 \mu \mathrm{g} /$ day (salbutamol equivalent). These categories have been used in previous studies. ${ }^{38,39}$

In all cases, multivariable models were fitted, adjusting for identified residual confounders, and model estimates were computed with $95 \%$ confidence intervals (CIs). The level of statistical significance was set at $5 \%$. The study had $90 \%$ power to detect a difference in the proportion of adherent patients of $7.7 \%$, with a two-sided significance of $5 \%$. All statistical analyses were carried out using Stata MP6 Version 12 and Stata SE Version 14 (StataCorp, College Station, TX, USA).

\section{Sensitivity analysis}

The analysis of the primary outcome was repeated in a subgroup of patients who had evidence of 9 months (270 days) of persistent use of FP/SAL medication. This meant that the patient received prescription for FP/SAL continuously over 9 months, with no more than 30 days between the dates of issue of prescriptions. Discontinuation was defined as having no repeat prescription of FP/SAL in 6 months (180 days).

The main analysis was carried out in cohorts deriving from all three matching ratio strategies, ie, 1:1, 1:2, and 1:3. A sensitivity analysis was carried out using cohorts that resulted from the 1:3 matching strategy only.

\section{Results}

\section{Patients}

After applying study criteria, 6,716 patients with asthma or COPD were available from the primary care databases. Details of specific inclusions and exclusions are shown in Figure S1. Of the 6,716 unmatched patients, 6,000 were likely to require co-payments (ie, registered in England) and 716 were not required to pay for prescriptions (ie, registered in Scotland). After matching, these figures were reduced to 1,640 patients in the payment cohort and 619 patients in the no-payment cohort. Of the payment cohort, 1,378 patients had asthma only and 262 patients had COPD, and of the no-payment cohort, 512 patients had asthma only and 107 patients had COPD (Table 1).

An overview of the variables with relevant differences between the cohorts is listed in Table S1. The proportions of patients matched 1:1, 1:2, or 1:3 are listed in Table S2 and show that the majority of patients were matched to three others.

Baseline characteristics of the matched cohorts, with disease groups combined, are listed in Tables 2 and 3. Patients had a mean age of 44 years in both cohorts; $47-48 \%$ of them were male, $28-30 \%$ of them were current smokers, and $35-36 \%$ of them had a body mass index (BMI) of $\geq 30$. All of these characteristics were well matched between cohorts, such that $P$-values for comparison were nonsignificant, and SDDs were $<10 \%$. Prevalence of comorbidities was similar between cohorts, and the median Charlson comorbidity index (CCI) was 4.0 (Table 2).

The average daily dose of SABA was $>600 \mu \mathrm{g} /$ day in $11.2 \%$ of the patients in the payment cohort and $13.1 \%$ of the patients in the no-payment cohort, and $\sim 15 \%$ of the patients in each cohort had two or more prescriptions of OCS, during the baseline year (Table 3). Approximately $42-45 \%$ of the patients with asthma had at least one severe exacerbation and 30-32\% of the patients with COPD had at least one moderate or severe exacerbation. All baseline variables had an SDD of $<10 \%$, indicating good balance between the matched cohorts. Definitions of the baseline variables in Table 3 are found in the Supplementary materials. Further baseline characteristics are listed in Table S3. Baseline characteristics for the asthma and COPD groups separately are listed in Tables S4-S6.

\section{Primary outcome}

During the outcome year, $34.3 \%$ of the patients in the payment cohort and $34.9 \%$ of the patients in the no-payment cohort had good adherence to FP/SAL therapy (ie, MPR

Table I Number of patients by cohort and disease group

\begin{tabular}{llllll}
\hline Disease & \multicolumn{2}{l}{ Unmatched $(\mathbf{n}=6,716)$} & & Matched $(\mathbf{n}=2,259)$ \\
\cline { 2 - 3 } \cline { 5 - 6 } group & $\begin{array}{l}\text { Payment } \\
\text { cohort }\end{array}$ & $\begin{array}{l}\text { No-payment } \\
\text { cohort }\end{array}$ & & $\begin{array}{l}\text { Payment } \\
\text { cohort }\end{array}$ & $\begin{array}{l}\text { No-payment } \\
\text { cohort }\end{array}$ \\
\hline Asthma & 4,882 & 582 & & 1,378 & 512 \\
COPD & 1,118 & 134 & & 262 & 107 \\
Total & 6,000 & 716 & & 1,640 & 619
\end{tabular}

Abbreviation: COPD, chronic obstructive pulmonary disease. 
Table 2 Baseline demographic characteristics and comorbidities in combined disease groups, by matched cohort

\begin{tabular}{|c|c|c|c|c|}
\hline Variables & $\begin{array}{l}\text { Payment cohort } \\
(n=I, 640)\end{array}$ & $\begin{array}{l}\text { No-payment cohort } \\
(n=619)\end{array}$ & $P$-value ${ }^{a}$ & SDD \\
\hline Index year, n (\%) & & & 0.176 & 5.9 \\
\hline 2012 & $879(53.6)$ & $322(52.0)$ & & \\
\hline 2013 & $509(31.0)$ & 191 (30.9) & & \\
\hline 2014 & $231(14.1)$ & $90(14.5)$ & & \\
\hline 2015 & $21(1.3)$ & $16(2.6)$ & & \\
\hline Age, mean (SD) & $44.0(11.1)$ & $44.4(11.2)$ & 0.341 & 3.7 \\
\hline Male, n (\%) & $775(47.3)$ & $298(48.1)$ & 0.707 & 1.8 \\
\hline Smoking status, n (\%) & & & 0.687 & 3.6 \\
\hline Never smoked & $762(46.5)$ & $275(44.4)$ & & \\
\hline Current smoker & $469(28.6)$ & $184(29.7)$ & & \\
\hline Exsmoker & 409 (24.9) & $160(25.8)$ & & \\
\hline BMI $\left(\mathrm{kg} / \mathrm{m}^{2}\right), \mathrm{n}(\%)$ & & & 0.356 & 2.5 \\
\hline$<18.5$ & $15(0.9)$ & II (I.8) & & \\
\hline $18.5-<25$ & $557(34.0)$ & $206(33.3)$ & & \\
\hline $25-<30$ & $478(29.1)$ & $186(30.0)$ & & \\
\hline$\geq 30$ & $590(36.0)$ & $216(34.9)$ & & \\
\hline \multicolumn{5}{|l|}{ Comorbidities, n (\%) } \\
\hline Cardiovascular disease & II 4 (7.0) & $4 \mid(6.6)$ & 0.784 & 1.3 \\
\hline Ischemic heart disease & $37(2.3)$ & $13(2.1)$ & 0.822 & I.I \\
\hline Hypertension & $218(13.3)$ & $80(12.9)$ & 0.817 & I.I \\
\hline Cancer & $142(8.7)$ & $70(11.3)$ & 0.054 & 8.8 \\
\hline Diabetes & $76(4.6)$ & $36(5.8)$ & 0.249 & 5.3 \\
\hline Rhinitis & $469(28.6)$ & 191 (30.9) & 0.292 & 4.9 \\
\hline Active rhinitis & $191(11.6)$ & $81(13.1)$ & 0.349 & 4.4 \\
\hline Gastroesophageal reflux disease & $166(10.1)$ & $73(11.8)$ & 0.249 & 5.3 \\
\hline Active gastroesophageal reflux disease & $12 \mid(7.4)$ & $49(7.9)$ & 0.666 & 2.0 \\
\hline Eczema & $486(29.6)$ & $170(27.5)$ & 0.311 & 4.8 \\
\hline Active eczema & $31(1.9)$ & $14(2.3)$ & 0.573 & 2.6 \\
\hline Pneumonia & $72(4.4)$ & $24(3.9)$ & 0.590 & 2.6 \\
\hline Oral candidiasis & $15(0.9)$ & $7(1.1)$ & 0.641 & 2.1 \\
\hline Charlson comorbidity index, median (IQR) & $4.0(4.0)$ & $4.0(4.0)$ & 0.554 & 3.1 \\
\hline
\end{tabular}

Note: aP-value estimated from Kruskal-Wallis equality-of-populations rank test, or the Pearson's chi-square test of independent categories, where appropriate. Abbreviations: SDD, standardized mean difference; SD, standard deviation; BMI, body mass index; IQR, interquartile range.

$\geq 80 \%$ ). This proportion was lower in patients with asthma (31.4\% in both cohorts) and higher in patients with COPD (49.6 and $51.4 \%$ in the payment and no-payment cohorts, respectively; Table 4). In unadjusted comparisons, adherence was not significantly different between cohorts $(P=0.801)$. The distribution of the adherence levels is shown graphically in Figure 1. Summary outcome data for the asthma and COPD groups separately are listed in Table S7.

When adjusting for potential confounders, the adjusted OR for adherence across both disease groups was 1.04 (95\% CI, 0.85-1.27; Table 5), comparing the payment cohort with the no-payment cohort, showing that adherence was similar between cohorts. Variables used for adjusting were selected based on the residual confounding observed (Table S8).

\section{Secondary outcomes}

During the outcome year, $62-64 \%$ of the patients with asthma achieved risk-domain control and $45-47 \%$ of the patients with
COPD achieved risk-domain disease control (Table 4). These proportions were not significantly different between cohorts. There were fewer exacerbations in the outcome year, but exacerbations remained similar between cohorts. Furthermore, there was no difference between acute respiratory events (in patients with asthma) and the average daily dose of SABA, when cohorts were compared in unadjusted analyses (Table 4).

When adjusting for residual confounders, the adjusted ORs for risk-domain control were 0.89 (95\% CI 0.71-1.11) in patients with asthma and 0.89 (95\% CI 0.53-1.48) in patients with COPD (Table 5). Adjusted RRs for severe exacerbations (or moderate/severe exacerbations in COPD) were 1.01 (95\% CI 0.85-1.21) in patients with asthma and 1.27 (95\% CI 0.98-1.65) in patients with COPD, comparing the payment cohort with the no-payment cohort. None of these associations were statistically significant. For patients with asthma, there was no difference between cohorts in terms of acute respiratory events (RR 1.10; 95\% CI 0.96-1.27), after adjustment 
Table 3 Baseline clinical characteristics in combined disease groups, by matched cohort

\begin{tabular}{|c|c|c|c|c|}
\hline Variables & $\begin{array}{l}\text { Payment cohort } \\
(n=1,640)\end{array}$ & $\begin{array}{l}\text { No-payment cohort } \\
(n=619)\end{array}$ & $P$-value ${ }^{a}$ & SDD \\
\hline Average daily dose of SABA ( $\mu$ g, salbutamol equivalent), $n(\%)$ & & & 0.597 & 6.9 \\
\hline 0 & $745(45.4)$ & $270(43.6)$ & & \\
\hline$>0-\leq 200$ & $397(24.2)$ & $144(23.3)$ & & \\
\hline$>200-\leq 400$ & $221(13.5)$ & $82(13.2)$ & & \\
\hline$>400-\leq 600$ & $94(5.7)$ & $42(6.8)$ & & \\
\hline$>600$ & $183(11.2)$ & $81(13.1)$ & & \\
\hline Any OCS prescriptions, $\mathrm{n}(\%)$ & & & 0.864 & 2.2 \\
\hline 0 & $1,132(69.0)$ & $420(67.9)$ & & \\
\hline I & $259(15.8)$ & $102(16.5)$ & & \\
\hline$\geq 2$ & $249(15.2)$ & $97(15.7)$ & & \\
\hline Antibiotic prescriptions, with LR consultation, ${ }^{b} \mathrm{n}(\%)$ & & & 0.432 & 5.5 \\
\hline 0 & $\mathrm{I}, 108(67.6)$ & $406(65.6)$ & & \\
\hline I & $317(19.3)$ & $119(19.2)$ & & \\
\hline$\geq 2$ & $215(13.1)$ & $94(15.2)$ & & \\
\hline A\&E attendances (at least I), n (\%) & $4(0.2)$ & $2(0.3)$ & 0.744 & 1.5 \\
\hline Outpatient visits ${ }^{\mathrm{c}}$ (at least I), n (\%) & $33(2.0)$ & $13(2.1)$ & 0.895 & 0.6 \\
\hline Moderate/severe exacerbations (COPD), n (\%) & & & 0.688 & 5.6 \\
\hline 0 & $94 I(57.4)$ & $339(54.8)$ & & \\
\hline 1 & $376(22.9)$ & 147 (23.7) & & \\
\hline 2 & $199(12.1)$ & $80(12.9)$ & & \\
\hline$\geq 3$ & $124(7.6)$ & $53(8.6)$ & & \\
\hline Severe exacerbations (asthma), n (\%) & & & 0.845 & 4.0 \\
\hline 0 & $\mathrm{I}, 14 \mathrm{I}(69.6)$ & $422(68.2)$ & & \\
\hline I & $306(18.7)$ & $117(18.9)$ & & \\
\hline 2 & $121(7.4)$ & $48(7.8)$ & & \\
\hline$\geq 3$ & $72(4.4)$ & $32(5.2)$ & & \\
\hline
\end{tabular}

Notes: ${ }^{\text {a }}$-value estimated from Kruskal-Wallis equality-of-populations rank test, or the Pearson's chi-square test of independent categories, where appropriate. 'LR consultations were identified by: Read codes (including asthma, COPD and LRTI); asthma/COPD review codes excluding any monitoring letter codes; and lung function and/ or asthma monitoring. 'Outpatient visits for asthma or LR code or generic outpatient code on same day as respiratory consultation.

Abbreviations: SDD, standardized mean difference; SABA, short-acting beta ${ }_{2}$ agonist; OCS, oral corticosteroids; LR, lower respiratory; LRTI, lower respiratory tract infection; A\&E, accident and emergency; COPD, chronic obstructive pulmonary disease.

for confounders. Proportional ORs for the average daily dose of SABA showed no difference in odds of being in a higher category of SABA dose in the payment cohort than in the no-payment cohort. Definitions of variables used to adjust the outcome models can be found in the Supplementary materials.

\section{Sensitivity analyses}

Since the adherence measure (MPR in a fixed 1-year period) included both implementation and persistence, a sensitivity analysis was performed, restricting the population to patients with at least 9 months of persistent use of FP/SAL after initiation. Of the matched cohorts, $80.2 \%$ of the patients in the payment cohort and $77.7 \%$ of the patients in the nopayment cohort met this criterion. In this subgroup, $42.1 \%$ of the patients in the payment cohort and $44.3 \%$ of the patients in the no-payment cohort had good adherence to treatment, in both disease groups combined (Table 4). In an adjusted model, there was no significant difference between cohorts in terms of adherence (Table S9).

Results were similar in sensitivity analysis restricted to patients matched 1:3 (Table 5). One exception, however, was in the comparison of severe exacerbations in the asthma group, which found that patients in the payment cohort had double the rate of exacerbations as patients in the no-payment cohort (RR, 2.03; 95\% CI, 1.05-3.93).

The main analysis investigated adherence in both disease groups combined, but an ad hoc sensitivity analysis was carried out in patients with asthma only. This was due to poorer matching of patients with COPD, evidenced by the presence of residual confounding. Patients with COPD were, therefore, excluded to test the robustness of the main results. In patients with asthma only, there was no difference in adherence between the two cohorts and no difference in the subgroup with 9 months of persistence (Table S9).

\section{Discussion}

This study showed that patients with asthma or COPD registered at general practices in England - who were likely to pay for their prescriptions - and patients with asthma or COPD registered in Scotland - who were not paying for prescriptions - had similar adherence to FP/SAL therapy. This was observed after matching by demographic characteristics and 
Table 4 Summary of outcomes, by cohort

\begin{tabular}{|c|c|c|c|}
\hline Variables, $\mathbf{n}(\%)$ & $\begin{array}{l}\text { Payment } \\
\text { cohort } \\
(n=I, 640)\end{array}$ & $\begin{array}{l}\text { No-payment } \\
\text { cohort }(n=6 \mid 9)\end{array}$ & $P$-value ${ }^{a}$ \\
\hline \multicolumn{4}{|c|}{ Adherence achieved (MPR >80\%) } \\
\hline Both disease groups & $563(34.3)$ & $216(34.9)$ & 0.801 \\
\hline Asthma group & $433(31.4)$ & I6I (3I.4) & 0.992 \\
\hline COPD group & $130(49.6)$ & $55(51.4)$ & 0.756 \\
\hline $\begin{array}{l}\text { With 9-month } \\
\text { persistence }\end{array}$ & $554(42.1)$ & $213(44.3)$ & 0.414 \\
\hline \multicolumn{4}{|c|}{ Risk domain control achieved } \\
\hline Asthma group & $854(62.0)$ & $325(63.5)$ & 0.549 \\
\hline COPD group & 117 (44.7) & $50(46.7)$ & 0.717 \\
\hline \multicolumn{2}{|l|}{ Severe asthma exacerbations } & & 0.950 \\
\hline 0 & $\mathrm{I}, 053(76.4)$ & $389(76.0)$ & \\
\hline 1 & $216(15.7)$ & $79(15.4)$ & \\
\hline 2 & $70(5.1)$ & $27(5.3)$ & \\
\hline$\geq 3$ & $39(2.8)$ & $17(3.3)$ & \\
\hline $\begin{array}{l}\text { Moderate/severe COPD } \\
\text { exacerbations }\end{array}$ & & & 0.393 \\
\hline 0 & $117(44.7)$ & $50(46.7)$ & \\
\hline 1 & $62(23.7)$ & $26(24.3)$ & \\
\hline 2 & $31(11.8)$ & $17(15.9)$ & \\
\hline$\geq 3$ & $52(19.8)$ & $14(13.1)$ & \\
\hline $\begin{array}{l}\text { Acute respiratory events, } \\
\text { asthma }\end{array}$ & & & 0.865 \\
\hline 0 & $854(62.0)$ & $325(63.5)$ & \\
\hline 1 & $34 I(24.7)$ & $121(23.6)$ & \\
\hline 2 & $103(7.5)$ & $40(7.8)$ & \\
\hline$\geq 3$ & $80(5.8)$ & $26(5.1)$ & \\
\hline $\begin{array}{l}\text { SABA, average daily } \\
\text { dose ( } \mu g / \text { day, salbutamol } \\
\text { equivalent), asthma }\end{array}$ & & & 0.706 \\
\hline 0 & $463(33.6)$ & $174(34.0)$ & \\
\hline$>0-\leq 200$ & $389(28.2)$ & $133(26.0)$ & \\
\hline$>200-\leq 400$ & $257(18.7)$ & $98(19.1)$ & \\
\hline$>400-\leq 600$ & $|2|(8.8)$ & $42(8.2)$ & \\
\hline$>600$ & $148(10.7)$ & $65(12.7)$ & \\
\hline $\begin{array}{l}\text { SABA, average daily } \\
\text { dose ( } \mu \text { g/day, salbutamol } \\
\text { equivalent), COPD }\end{array}$ & & & 0.155 \\
\hline 0 & $74(28.2)$ & $33(30.8)$ & \\
\hline$>0-\leq 200$ & $52(19.8)$ & $14(13.1)$ & \\
\hline$>200-\leq 400$ & $48(18.3)$ & $28(26.2)$ & \\
\hline$>400-\leq 600$ & $46(17.6)$ & $12(11.2)$ & \\
\hline$>600$ & $42(16.0)$ & $20(18.7)$ & \\
\hline
\end{tabular}

Notes: aP-value estimated from Kruskal-Wallis equality-of-populations rank test, or the Pearson's chi-square test of independent categories, where appropriate. ' $\mathrm{A}$ total of $80.2 \%$ of the patients in the payment cohort and $77.7 \%$ of the patients in the no-payment cohort had 9 months of persistent use of FP/SAL.

Abbreviations: MPR, medication possession ratio; COPD, chronic obstructive pulmonary disease; SABA, short-acting beta ${ }_{2}$ agonist; FP/SAL, fluticasone propionate/ salmeterol xinafoate.

indicators of disease severity and after adjusting for residual confounding.

The level of adherence to maintenance therapy observed in this study $-\sim 35 \%$ in patients with asthma and $50 \%$ in patients with COPD - was within the range reported in

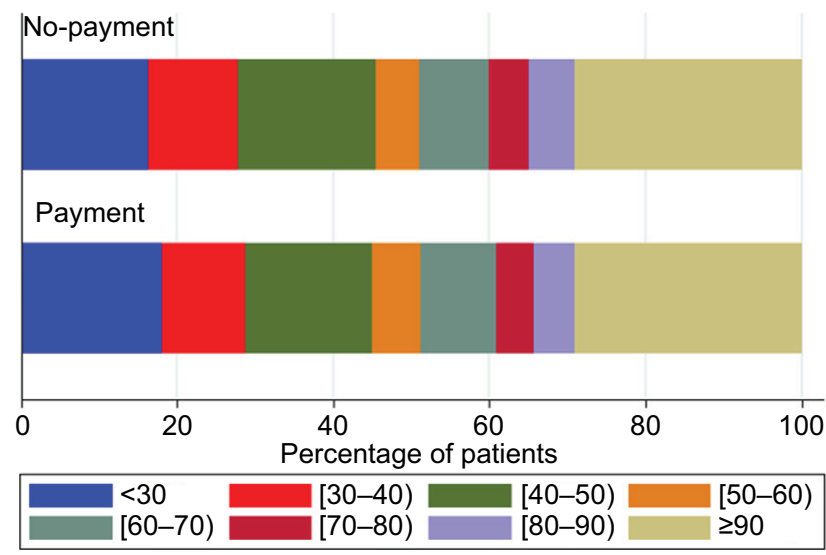

Figure I Distribution of medication possession ratio (\%) in matched cohorts.

other studies. ${ }^{9,40-43}$ In terms of the association between copayments for prescription and adherence, the current study was not consistent with recent literature. A meta-analysis published in $2013,{ }^{44}$ which included only US studies of varying medication types, estimated an overall increase in odds of nonadherence of $11 \%$ in co-payment versus no co-payment. The authors noted several limitations of the results, however - that the follow-up times varied between studies, between 3 months and 2 years, and that the quality of studies was poor in some cases. Another meta-analysis on studies done in the USA or Canada ${ }^{45}$ found that 56 of the 66 studies reported an inverse relationship between co-payment and adherence, with 10 studies reporting a nonsignificant relationship, or limited data to detect a relationship. These studies also covered a range of medication types. The authors acknowledged that the analysis of adherence should account for factors affecting adherence, such as disease severity, and that this was not done consistently across the studies included. The review covered two studies on ICS. One study, using electronic medical records, did not find a difference in adherence between co-payment levels. ${ }^{46}$ The second study, using pharmacy records, showed a significant negative association with cumulative co-payment level and implementation adherence..$^{40}$ Another study in the same patient population in Pennsylvania showed that patients with higher co-payment costs were less likely to initiate asthma medication. ${ }^{47} \mathrm{~A}$ discrete choice experiment of patients with COPD from the USA showed medication costs for the patients to be an important factor in treatment decisions. ${ }^{48}$

An explanation for the inconsistency between the current study and what is reported in the literature could be publication bias: negative studies tend to be less likely to be published, ${ }^{49}$ but this only counts for studies with the association between co-payment and adherence as their main 
Table 5 Results of adjusted outcome models

\begin{tabular}{|c|c|c|c|c|}
\hline \multirow[t]{2}{*}{ Outcome variable } & \multicolumn{2}{|c|}{ All matching ratios used $(\mathrm{N}=\mathbf{2}, 259)$} & \multicolumn{2}{|c|}{$\begin{array}{l}\text { Only I:3 matching ratio used } \\
(N=I, 928)\end{array}$} \\
\hline & $\begin{array}{l}\text { Adjusted odds ratio/rate } \\
\text { ratio }^{\text {a }} \text { (with } 95 \% \mathrm{CI} \text { ) }\end{array}$ & $P$-value & $\begin{array}{l}\text { Adjusted odds ratio/rate } \\
\text { ratio }^{a} \text { (with } 95 \% \mathrm{CI} \text { ) }\end{array}$ & P-value \\
\hline \multicolumn{5}{|l|}{ Combined disease groups } \\
\hline Adherence $^{\mathrm{b}}$ & $1.04(0.85-1.27)$ & 0.704 & $\mathrm{I} .58(0.80-3.14)$ & 0.191 \\
\hline \multicolumn{5}{|l|}{ Asthma } \\
\hline Risk-domain controlb & $0.89(0.7 I-I . I I)$ & 0.294 & $0.56(0.27-1.17)$ & 0.125 \\
\hline Number of severe exacerbations ${ }^{c}$ & $1.01(0.85-1.21)$ & 0.907 & $2.03(1.05-3.93)$ & 0.035 \\
\hline Number of acute respiratory events ${ }^{d}$ & $\mathrm{I} .10(0.96-1.27)$ & 0.163 & $1.56(0.99-2.47)$ & 0.055 \\
\hline SABA average daily dose ${ }^{e}$ & $1.05(0.86-1.27)$ & 0.655 & $1.22(0.6 I-2.47)$ & 0.576 \\
\hline \multicolumn{5}{|l|}{ COPD } \\
\hline Risk-domain controlf $^{f}$ & $0.89(0.53-1.48)$ & 0.641 & NC & \\
\hline Number of moderate/severe exacerbations ${ }^{g}$ & $1.27(0.98-1.65)$ & 0.067 & NC & \\
\hline SABA average daily dose $\mathrm{h}^{\mathrm{h}}$ & $1.03(0.65-1.63)$ & 0.907 & NC & \\
\hline
\end{tabular}

Notes: NC means model did not reach convergence. ${ }^{a}$ Odds/rate ratios compare payment cohort with no-payment cohort. ${ }^{\mathrm{b} A d j u s t e d}$ by antibiotic prescriptions with lower respiratory indication. 'Adjusted by acute OCS courses (sensitive definition) LTRA prescription, and maintenance OCS prescription. ${ }^{\mathrm{d} A d j u s t e d}$ by antibiotic prescriptions with lower respiratory indication and LTRA prescription. ${ }^{e} A d j u s t e d$ by the average daily dose of SABA. ${ }^{\mathrm{f}} \mathrm{Adjusted}$ by eczema, cancer, active gastroesophageal reflux disease, rhinitis, number of SABA inhalers, any OCS prescription and acute OCS course (sensitive definition). ${ }^{8} A d j u s t e d$ by ICS prescriptions, acute OCS

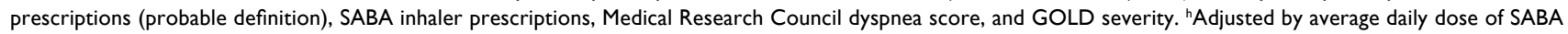
and GOLD severity.

Abbreviations: $\mathrm{Cl}$, confidence interval; SABA, short-acting beta ${ }_{2}$ agonist; COPD, chronic obstructive pulmonary disease; NC, no convergence; OCS, oral corticosteroids; LTRA, leukotriene receptor antagonist; ICS, inhaled corticosteroids; GOLD, Global Initiative for Chronic Obstructive Lung Disease.

objective. The cited studies came from the USA and Canada. Cultural and socioeconomic differences existing between these countries and the UK could be another explanation for the discrepancy in findings.

This study found no difference in disease outcomes between patients likely paying for prescriptions and patients not paying for prescriptions in the majority of cases. The association between adherence and effectiveness of treatment has been demonstrated previously, ${ }^{9}$ and hence it is unsurprising that matched cohorts with similar adherence would observe similar disease outcomes. However, there was some inconsistency in the results: patients in the payment cohort were found to have significantly more severe asthma exacerbations than those in the no-payment cohort when the analysis was restricted to cohorts derived from one matching strategy, rather than a mixture of matching strategies. This inconsistency cannot easily be explained but is potentially an anomaly as the results were consistent on all other endpoints.

The strength of this study is its size and the real-life data used, which is likely to be representative of patients with asthma and patients with COPD. Furthermore, the length of follow-up allowed for a good measure of adherence to be estimated. As this was an observational study to compare two cohorts, methods were applied to ensure that the cohorts were as similar as possible, so that associations with the exposure (co-payment of prescriptions, or no co-payment of prescriptions) could be studied. The study design included matching patients based on important demographic and clinical factors and adjusting models by further potential confounders. When the level of residual confounding was high, as was observed in the COPD group, ad hoc analyses were carried out in the asthma group only, but the exclusion of the COPD group did not appear to impact the results.

\section{Limitations}

Limitations of the current study include the possibility of residual confounding. Despite matching methods and adjustment for measured confounders, the nature of the study being observational, rather than a randomized controlled trial - is such that confounding by unmeasured variables may be present in the results. Medication-taking behavior can be affected by many factors. Such factors may be subjective and unique to the patients - for example, attitude toward the health care system and personal perception of their disease. This is an added difficulty in the analysis of adherence. ${ }^{50}$ Furthermore, the two cohorts being compared in this study were from different geographical locations in the UK, which are known to differ in terms of chronic disease and life expectancy. ${ }^{51,52}$ Matching by the history of disease outcomes will have gone some way to alleviate differences between patients in England and Scotland, and the study cohorts were well-matched in terms of comorbidities. Other potential differences, such as income of the patients, 
could not be accounted for in these data. The results did not include practice-level clustering and, therefore, may have been affected by potential differences between practices, such as the level of health education offered. In addition, despite the quality of the databases used, it cannot be guaranteed that all information is complete. ${ }^{53}$

The study did not distinguish between the three components of adherence (initiation, implementation, and persistence). By requiring at least two prescriptions for a patient to be included in the study, we excluded patients who did not initiate their prescribed treatment. Therefore, our study was not able to detect differences in that aspect of adherence. In a sensitivity analysis restricting the population to patients with at least 9 months of persistent FP/SAL use, we showed that our conclusion of no difference in adherence between the payment and no-payment cohorts was not driven by the inclusion of nonpersistent patients.

We did not exclude patients who switched to other ICS medication, and such patients will have appeared to have poor adherence to FP/SAL therapy in our dataset. However, since the observed adherence levels were within the range of results from other studies, and both cohorts are likely to have been affected equally, we do not think this affected the results.

Our algorithm for MPR did not adjust observed prescription dates and durations for stockpiling, dose changes, or medication switches, which could have resulted in a reduced precision of adherence quantification.

The study endeavored to exclude patients registered in general practices in England who were exempt from prescription charges. This was done by searching for common reasons for exemption, such as pregnancy, and by searching for a record of exemption status. In doing this, the study relied on the accuracy of the primary care source databases. It is likely that the vast majority of patients with exemptions have been excluded, but it remains a possibility that a small proportion of exempt patients were in the study sample.

\section{Conclusion}

Patient adherence is vital if treatment is to be effective. At a time when prescription costs are high and put a strain on the health care system, ${ }^{54}$ it is important to ascertain whether measures to relieve the strain - such as co-payments - have an adverse effect on adherence to treatment, and consequently, on patient outcomes. In this study, there was no difference in adherence between matched patients registered in England and Scotland, suggesting that prescription charges do not have an impact on adherence to maintenance therapy for asthma or COPD.

\section{Acknowledgments}

The authors thank Derek Skinner for data extraction, Martina Stagno d'Alcontres and Susannah Thornhill for medical writing, and Lakmini Bulathsinhala for performing quality checks of statistical code and study support. This study was funded by TEVA Europe.

\section{Author contributions}

BV, JFMvB, DR, MM, and DBP developed the research question. JV and DBP developed the study design. JV conducted the data preparation and analyses. LML drafted the manuscript. All authors were involved in the interpretation of the data and the critical review and revision of the manuscript. All authors read and approved the final manuscript.

\section{Disclosure}

JV and LML are employed by Observational \& Pragmatic Research Institute Pte Ltd, Singapore, which receives funding from UK National Health Service, British Lung Foundation, Aerocrine, AKL Ltd, Almirall, AstraZeneca, Boehringer Ingelheim, Chiesi, Eli Lilly, GlaxoSmithKline, Meda, Merck, Mundipharma, Napp, Novartis, Orion, Pfizer, Respiratory Effectiveness Group, Takeda, Teva Pharmaceuticals, and Zentiva. JFMvB's institution has received study grants from GlaxoSmithKline, Novartis, AstraZeneca, and Boehringer Ingelheim and consultancy fees from AstraZeneca. DR has received personal fees for lectures from Chiesi, AstraZeneca, Takeda, Boehringer Ingelheim, Novartis, and Teva and for advisory boards from Teva, Chiesi, Boehringer Ingelheim, and Novartis. MM has received speaker fees from Boehringer Ingelheim, AstraZeneca, Chiesi, GlaxoSmithKline, Menarini, Teva, Grifols, and Novartis and consulting fees from Bayer Schering, Boehringer Ingelheim, GlaxoSmithKline, Gebro Pharma, CLS Behring, Cipla, MediImmune, Mereo Biopharma, Teva, Novartis, and Grifols. DBP has a board membership with Aerocrine, Almirall, Amgen, AstraZeneca, Boehringer Ingelheim, Chiesi, Meda, Mundipharma, Napp, Novartis, and Teva; received consultancy fees from Almirall, Amgen, AstraZeneca, Boehringer Ingelheim, Chiesi, GlaxoSmithKline, Meda, Mundipharma, Napp, Novartis, Pfizer, Teva, and Zentiva; grants/grants pending with UK National Health Service, British Lung Foundation, Aerocrine, AstraZeneca, Boehringer Ingelheim, Chiesi, Eli Lilly, GlaxoSmithKline, Meda, Merck, Mundipharma, Novartis, Orion, Pfizer, Respiratory Effectiveness Group, Takeda, Teva, and Zentiva; received payments for lectures/speaking from Almirall, AstraZeneca, Boehringer Ingelheim, Chiesi, Cipla, GlaxoSmithKline, Kyorin, Meda, Merck, Mundipharma, 
Novartis, Pfizer, SkyePharma, Takeda, and Teva; received payment for manuscript preparation from Mundipharma and Teva; received patents (planned, pending, or issued) from AKL Ltd.; received payment for the development of educational materials from GlaxoSmithKline, Novartis; has stock/stock options with shares in AKL Ltd, which produces phytopharmaceuticals and owns $80 \%$ of research in Real Life Ltd, $75 \%$ of the social enterprise Optimum Patient Care Ltd, and $75 \%$ of Observational \& Pragmatic Research Institute Pte Ltd; received payment for travel/accommodations/ meeting expenses from Aerocrine, Boehringer Ingelheim, Mundipharma, Napp, Novartis, and Teva; funding for patient enrolment or completion of research: Almirral, Chiesi, Teva, and Zentiva; is a peer reviewer for grant committees of Medical Research Council (2014), Efficacy and Mechanism Evaluation Programme (2012), and HTA (2014); and received unrestricted funding for investigator-initiated studies from Aerocrine, AKL Ltd, Almirall, Boehringer Ingelheim, Chiesi, Meda, Mundipharma, Napp, Novartis, Orion, Takeda, Teva, and Zentiva. The authors report no other conflicts of interest in this work.

\section{References}

1. World Health Organisation. Global Surveillance, Prevention and Control of Chronic Respiratory Diseases: A Comprehensive Approach; 2007. Available from: http://www.who.int/gard/publications/GARD $\% 20$ Book\%202007.pdf. Accessed October 26, 2016.

2. Osterberg L, Blaschke T. Adherence to medication. $N$ Engl J Med. 2005;353(5):487-497.

3. Vrijens B, De Geest S, Hughes DA, et al; ABC Project Team. A new taxonomy for describing and defining adherence to medications. $\mathrm{Br} \mathrm{J}$ Clin Pharmacol. 2012;73(5):691-705.

4. Covvey JR, Mullen AB, Ryan M, et al. A comparison of medication adherence/persistence for asthma and chronic obstructive pulmonary disease in the United Kingdom. Int J Clin Pract. 2014;68(10):1200-1208.

5. Mueller S, Wilke T, Bechtel B, Punekar YS, Mitzner K, Virchow JC. Non-persistence and non-adherence to long-acting COPD medication therapy: a retrospective cohort study based on a large German claims dataset. Respir Med. 2017;122:1-11.

6. Wu AC, Butler MG, Li L, et al. Primary adherence to controller medications for asthma is poor. Ann Am Thorac Soc. 2015;12(2):161-166.

7. Belleudi V, Di Martino M, Cascini S, et al. The impact of adherence to inhaled drugs on 5-year survival in COPD patients: a time dependent approach. Pharmacoepidemiol Drug Saf. 2016;25(11):1295-1304.

8. Makhinova T, Barner JC, Richards KM, Rascati KL. Asthma controller medication adherence, risk of exacerbation, and use of rescue agents among Texas medicaid patients with persistent asthma. J Manag Care Spec Pharm. 2015;21(12):1124-1132.

9. van Boven JF, Chavannes NH, van der Molen T, Rutten-van Molken MP, Postma MJ, Vegter S. Clinical and economic impact of non-adherence in COPD: a systematic review. Respir Med. 2014;108(1):103-113.

10. Dima AL, Hernandez G, Cunillera O, Ferrer M, de Bruin M; ASTROLAB Group. Asthma inhaler adherence determinants in adults: systematic review of observational data. Eur Respir J. 2015;45(4):994-1018.

11. Cooper V, Metcalf L, Versnel J, Upton J, Walker S, Horne R. Patientreported side effects, concerns and adherence to corticosteroid treatment for asthma, and comparison with physician estimates of side-effect prevalence: a UK-wide, cross-sectional study. NPJ Prim Care Respir Med. 2015;25:15026.
12. Darba J, Ramirez G, Sicras A, Francoli P, Torvinen S, Sanchez-de la Rosa R. The importance of inhaler devices: the choice of inhaler device may lead to suboptimal adherence in COPD patients. Int J Chron Obstruct Pulmon Dis. 2015;10:2335-2345.

13. Lurslurchachai L, Krauskopf K, Roy A, Halm EA, Leventhal H, Wisnivesky JP. Metered dose inhaler technique among inner-city asthmatics and its association with asthma medication adherence. Clin Respir J. 2014;8(4):397-403.

14. Barry M, Usher C, Tilson L. Public drug expenditure in the Republic of Ireland. Expert Rev Pharmacoecon Outcomes Res. 2010;10(3):239-245.

15. Hynd A, Roughead EE, Preen DB, Glover J, Bulsara M, Semmens J. Increased patient co-payments and changes in PBS-subsidised prescription medicines dispensed in Western Australia. Aust NZJ Public Health. 2009;33(3):246-252.

16. Lee IH, Bloor K, Hewitt C, Maynard A. The effects of new pricing and copayment schemes for pharmaceuticals in South Korea. Health Policy. 2012;104(1):40-49.

17. McPake B, Normand C. Health Economics: An International Perspective. 2nd ed. Routledge: Oxon; 2008.

18. Hynd A, Roughead EE, Preen DB, Glover J, Bulsara M, Semmens J. The impact of co-payment increases on dispensings of governmentsubsidised medicines in Australia. Pharmacoepidemiol Drug Saf. 2008;17(11):1091-1099.

19. Warman KL, Silver EJ, Stein RE. Asthma symptoms, morbidity, and antiinflammatory use in inner-city children. Pediatrics. 2001;108(2):277-282.

20. Rice T, Matsuoka KY. The impact of cost-sharing on appropriate utilization and health status: a review of the literature on seniors. Med Care Res Rev. 2004;61(4):415-452.

21. GOV.UK [webpage on the Internet]. Written statement to Parliament. NHS charges from April 2016; 2016. Available from: https://www. gov.uk/government/speeches/nhs-charges-from-april-2016. Accessed January 4, 2017.

22. NHS Lothian [webpage on the Internet]. Abolition of Prescription Charges. Important Information on Prescription Charges; 2016. Available from: http://www.nhslothian.scot.nhs.uk/YourRights/PrescriptionCharges/Pages/default.aspx. Accessed January 4, 2017.

23. Optimum Patient Care Research Database (OPCRD) [webpage on the Internet]. Our Databases. Available from: http://optimumpatientcare. org/our-database/. Accessed December 13, 2016.

24. The Clinical Practice Research Datalink [homepage on the Internet]. Available from: https://www.cprd.com/home/. Accessed October 26, 2016.

25. Herrett E, Thomas SL, Schoonen WM, Smeeth L, Hall AJ. Validation and validity of diagnoses in the General Practice Research Database: a systematic review. Br J Clin Pharmacol. 2010;69(1):4-14.

26. Lim D, Small I, Wolfe S, et al. Real world effectiveness of changing fixed dose combination therapy from Seretide ${ }^{\circledR}$ MDI To Flutiform ${ }^{\circledR}$ in UK asthma Patients. Oral paper presentation at the IPCRG 7th World Conference of the International Primary Care Respiratory Group (IPCRG); May 21-24, 2014; Athens, Greece.

27. Price D, Kaplan A, Jones R, et al. Long-acting muscarinic antagonist use in adults with asthma: real-life prescribing and outcomes of add-on therapy with tiotropium bromide. J Asthma Allergy. 2015;8:1-13.

28. Price D, Wilson AM, Chisholm A, et al. Predicting frequent asthma exacerbations using blood eosinophil count and other patient data routinely available in clinical practice. J Asthma Allergy. 2016;9:1-12.

29. Price DB, Colice G, Israel E, et al. Add-on LABA in a separate inhaler as asthma step-up therapy versus increased dose of ICS or ICS/LABA combination inhaler. ERJ Open Res. 2016;2(2):00106.

30. Blakey JD, Price DB, Pizzichini E, et al. Identifying risk of future asthma attacks using UK medical record data: a respiratory effectiveness group initiative. J Allergy Clin Immunol Pract. Epub 2016 Dec 22.

31. Respiratory Effectiveness Group [webpage on the Internet]. About Us. Available from: http://effectivenessevaluation.org/about-us/. Accessed October 26, 2016.

32. European Network of Centres for Pharmacoepidemiology and Pharmacovigilance [homepage on the Internet]. Available from: http://www. encepp.eu/. Accessed October 26, 2016. 
33. Andrade SE, Kahler KH, Frech F, Chan KA. Methods for evaluation of medication adherence and persistence using automated databases. Pharmacoepidemiol Drug Saf. 2006;15(8):565-574. discussion 567-575.

34. Chung KF, Wenzel SE, Brozek JL, et al. International ERS/ATS guidelines on definition, evaluation and treatment of severe asthma. Eur Respir J. 2014;43(2):343-373.

35. Groenwold RH, de Vries F, de Boer A, et al. Balance measures for propensity score methods: a clinical example on beta-agonist use and the risk of myocardial infarction. Pharmacoepidemiol Drug Saf. 2011;20(11):1130-1137.

36. Rubin DB. The design versus the analysis of observational studies for causal effects: parallels with the design of randomized trials. Stat Med. 2007;26(1):20-36

37. Austin PC. An introduction to propensity score methods for reducing the effects of confounding in observational studies. Multivariate Behav Res. 2011;46(3):399-424.

38. Price D, Thomas V, von Ziegenweidt J, Gould S, Hutton C, King C. Switching patients from other inhaled corticosteroid devices to the Easyhaler((R)): historical, matched-cohort study of real-life asthma patients. J Asthma Allergy. 2014;7:31-51.

39. Roche N, Postma DS, Colice G, et al. Differential effects of inhaled corticosteroids in smokers/ex-smokers and nonsmokers with asthma. Am J Respir Crit Care Med. 2015;191(8):960-964.

40. Bender BG, Pedan A, Varasteh LT. Adherence and persistence with fluticasone propionate/salmeterol combination therapy. J Allergy Clin Immunol. 2006;118(4):899-904.

41. Charles MS, Blanchette CM, Silver H, Lavallee D, Dalal AA, Mapel D. Adherence to controller therapy for chronic obstructive pulmonary disease: a review. Curr Med Res Opin. 2010;26(10):2421-2429.

42. Sumino K, Cabana MD. Medication adherence in asthma patients. Curr Opin Pulm Med. 2013;19(1):49-53.

43. Toy EL, Beaulieu NU, McHale JM, et al. Treatment of COPD: relationships between daily dosing frequency, adherence, resource use, and costs. Respir Med. 2011;105(3):435-441.

44. Sinnott SJ, Buckley C, O'Riordan D, Bradley C, Whelton H. The effect of copayments for prescriptions on adherence to prescription medicines in publicly insured populations; a systematic review and meta-analysis. PLoS One. 2013;8(5):e64914.
45. Eaddy MT, Cook CL, O’Day K, Burch SP, Cantrell CR. How patient cost-sharing trends affect adherence and outcomes: a literature review. P T. 2012;37(1):45-55.

46. Williams LK, Joseph CL, Peterson EL, et al. Race-ethnicity, crime, and other factors associated with adherence to inhaled corticosteroids J Allergy Clin Immunol. 2007;119(1):168-175.

47. Berger Z, Kimbrough W, Gillespie C, et al. Lower copay and oral administration: predictors of first-fill adherence to new asthma prescriptions. Am Health Drug Benefits. 2009;2(4):174-180.

48. Kawata AK, Kleinman L, Harding G, Ramachandran S. Evaluation of patient preference and willingness to pay for attributes of maintenance medication for chronic obstructive pulmonary disease (COPD). Patient. 2014;7(4):413-426.

49. Song F, Parekh S, Hooper L, et al. Dissemination and publication of research findings: an updated review of related biases. Health Technol Assess. 2010;14(8):iii,ix-xi,1-193.

50. Kardas P, Lewek P, Matyjaszczyk M. Determinants of patient adherence: a review of systematic reviews. Front Pharmacol. 2013;4:91.

51. Office for National Statistics [webpage on the Internet]. Life expectancy at birth and at age 65 by local areas in the United Kingdom: 2006-08 to $2010-12$; 2014. Available from: https://www.ons.gov.uk/peoplepopulationandcommunity/birthsdeathsandmarriages/lifeexpectancies/ bulletins/lifeexpectancyatbirthandatage65bylocalareasintheunitedkingdom/2014-04-16. Accessed December 20, 2016.

52. Scarborough P, Morgan RD, Webster P, Rayner M. Differences in coronary heart disease, stroke and cancer mortality rates between England, Wales, Scotland and Northern Ireland: the role of diet and nutrition. BMJ Open. 2011;1(1):e000263.

53. Herrett E, Shah AD, Boggon R, et al. Completeness and diagnostic validity of recording acute myocardial infarction events in primary care, hospital care, disease registry, and national mortality records: cohort study. BMJ. 2013;346:f2350.

54. Hitiris T. Prescription Charges in the United Kingdom: A Critical Review. Department of Economics, University of York. Discussion paper 2000. Available from: https://www.york.ac.uk/media/economics/ documents/discussionpapers/2000/0004.pdf. Accessed February 21, 2017.
Pragmatic and Observational Research

\section{Publish your work in this journal}

Pragmatic and Observational Research is an international, peer-reviewed open access journal that publishes data from studies designed to reflect more closely medical interventions in real-world clinical practice compared with classical randomized controlled trials (RCTs). The manuscript management system is completely online and includes a very quick and fair peer-review
Dovepress

system. Visit http://www.dovepress.com/testimonials.php to read real quotes from published authors. 